\title{
The risk of suicide in chronic pain patients
}

\author{
Joseph V Pergolizzi Jr ${ }^{1}$, Steven Passik ${ }^{2}$, Jo Ann LeQuang ${ }^{1}$, Daniel Colucci ${ }^{3}$, Robert Taylor ${ }^{1}$, Robert B Raffa ${ }^{4}$ and John Bisney ${ }^{*}$ \\ ${ }^{1}$ NEMA Research, Inc., Naples, Fla, USA \\ ${ }^{2}$ Scientific Affairs, Education and Policy, Collegium Pharmaceutical, Canton, USA \\ ${ }^{3}$ Department of Bioengineering, Northeastern University, Boston, USA \\ ${ }^{4}$ Adjunct Professor, University of Arizona College of Pharmacy, Tucson, Ariz.; Prof Emeritus, Temple University School of Pharmacy, Philadelphia, USA
}

\begin{abstract}
Chronic pain patients are at elevated risk for suicide, but suicidality as an escape from persistent suffering is not the full picture. Chronic pain is comorbid with mental health conditions, in particular depression and personality disorders, which carries with it elevated risk for suicidality. The neural networks involved in chronic pain processing overlap those with depression. Affective disorders such as catastrophizing may not only exacerbate painful symptoms but also increase the risk of suicidal ideation independent of pain intensity and depression. Insomnia, likewise common in the chronic pain population, has also emerged as a risk factor for suicide. The use of certain drugs has also been linked to increased suicidality. Thus, an interplay of factors may enhance suicide risk in the chronic pain population. Migraine is more associated with suicidality than other disease conditions, while neuropathic pain seems to confer no additional risk of suicide. The role of cytokine imbalances and inflammatory processes is being explored as a risk factor for suicide in patients with chronic pain and/or mental health disorders. Substance abuse may also play a role in increasing the risk of suicide in chronic pain patients. The chronic pain population is a particularly vulnerable population with respect to suicidality and clinicians should be mindful of these risks in treating chronic pain patients.
\end{abstract}

\section{Introduction}

Suicide is a global public health problem and may represent about $1.4 \%$ of all deaths and is the $17^{\text {th }}$ leading cause of death in the world [1]. For every suicide victim, there are as many as 20 others who attempt suicide [1]. Suicide was the $10^{\text {th }}$ most frequent cause of death in the United States (US) in 2014 (accounting for 42,826 deaths) and appears to be trending upward [2]; the age-adjusted suicide rate in 2014 was $24 \%$ higher than it was in 1999 [3]. Of the top 15 causes of death in the US, suicide has the highest male to female ratio (3.6) and the lowest black to white ratio (0.4) [2]. In 2014, about 1.1 million American adults attempted suicide and 9.4 million reported having serious thoughts about committing suicide (without making an attempt) [4].

Suicidality is a complex phenomenon and may occur when the individual simultaneously faces both extreme stress and a limited ability to cope. Indeed, the individual may perceive suicide as the only means of escaping physical and/or emotional pain [5]. Chronic pain patients are at double the risk of suicide compared to others not in chronic pain, with a lifetime prevalence of attempted suicide ranging from $5 \%$ to $14 \%$ [6]. Chronic pain may create life-altering, overwhelming stress, and limited access to medical care, social support, and/or effective analgesia can seem overwhelming.

In a survey of 1,512 chronic pain patients, $32 \%$ of respondents reported they had some form of suicidal ideation [7]. There are likely multiple reasons for this. Chronic pain is a devastating psychosocial life event that can reduce function, limit the patient's ability to pursue everyday activities, and cause unrelenting suffering. Many chronic pain patients suffer from comorbid psychiatric disorders; this condition is so common that is has been termed "dual diagnosis." In addition, chronic pain patients are often prescribed polypharmacy, which may alter biochemistry in unintended ways and, in so doing, exacerbate distress and suicidal ideation. The aim of this narrative review is to explore what is currently understood about suicidal behaviours in chronic pain patients.

\section{Methods}

The PubMed databases were searched for the keyword combination "chronic pain + suicide" and articles obtained were reviewed. In some cases, references from those articles were further explored. Some of our references, in particular for background statistics, come from websites maintained by the Centres for Disease Control and Prevention and the World Health Organization. This is a narrative review rather than a systematic review.

\section{Suicide Terminology}

Suicidality must be considered as a continuum. At one end are random ideas and vague thoughts of self-harm and at the other end is completed suicide; between these two extremes are thoughts, plans, and attempts, in that order [8]. Suicidal ideation-entertaining thoughts of suicide-is considered an important precursor to attempted suicide or suicide $[9,10]$. The most robust predictor of suicide is a prior attempted suicide $[11,12]$. (Table 1 ).

Suicide risk may be defined along two dimensions: the baseline risk (an underlying ideation that remains relatively constant over time) and acute risk (risk that fluctuates in response to stressors and situations) [13]. Thus, suicide risk is dynamic over a lifetime.

*Correspondence to: John Bisney, NEMA Research, Inc., 868 106th Ave North, Naples, FL 34108, USA, Tel: 979864 4479, E-mail: john@leqmedical.com

Key words: chronic pain, suicide

Received: June 06, 2018; Accepted: September 12, 2018; Published: September 17,2018 
Table 1. Terminology used in this narrative review

\begin{tabular}{|l|l|}
\hline Term & Definition \\
\hline Suicidality & $\begin{array}{l}\text { Collective term for all types of thoughts and behaviors related to } \\
\text { suicide }\end{array}$ \\
\hline Suicide risk & Factor(s) that may increase the likelihood of suicide \\
\hline Suicidal ideation & Thoughts about engaging in suicide-related behavior \\
\hline Suicidal intent & The firm conviction that one will commit suicide \\
\hline Suicide plan & $\begin{array}{l}\text { A firm plan as to how one would commit suicide, including means, } \\
\text { location, timing, and so on }\end{array}$ \\
\hline Attempted suicide & An unsuccessful effort to end one's life \\
\hline Completed suicide & Death by suicide \\
\hline
\end{tabular}

\section{The risk of suicide in the population of chronic pain patients}

Chronic pain has been associated with higher rates of suicidal ideation, suicide attempts, and completed suicides [6]. The prevalence of suicidal ideation in chronic pain patients is about three times as great as among those who do not suffer from chronic pain $[14,15]$. Explanations for suicidality in chronic pain patients may first include the obvious, namely that individuals with severe, relentless pain and concomitant dysfunction might feel hopeless and consider suicide a way to end their suffering [6]. It has been speculated that certain chronic painful conditions may activate indirect mechanisms such that a mental health disorder is triggered, which then leads to suicidal ideation or suicide attempts [14]. Serotonergic abnormalities have been suggested as playing a role in suicidal ideation and attempted suicide [16].

The risk factors for suicide in general may be grouped into five domains: psychiatric disorders; risks associated with specific personality traits; psychosocial life events, including chronic illness; genetic and familial factors; and neurochemical and biochemical influences $[17,18]$. Predisposing factors include life events, opportunity, and environmental factors; potentially modifying factors include social support, psychiatric care, and cognitive flexibility [17]. Physical problems, including pain and loss of function, have been specifically observed as a precipitating factor in suicides of geriatric individuals [19].

A number of risk factors for suicidality in chronic pain patients have recently been identified [6]. (Table 2). Pain itself is a risk factor, although some studies have found equivocal results in terms of whether worsening pain intensities could be associated with exacerbated suicide risks in a dose-dependent fashion [20,21]. However, very severe pain confers a much greater risk for suicide than mild pain [20,21]. A retrospective study based on the 1999 Large Health Survey of Veterans $(n=260,254)$ found that completed suicide could be associated with extreme pain intensity levels [22]. After controlling for psychiatric conditions and demographic data, the suicide rates for those with very mild pain compared to those with very severe pain was 45.27 versus 80.65 , respectively, per 100,000 patient-years [22]. A meta-analysis of 31 studies found the risk of suicide among those with physical pain was higher than in those without pain [23]. People dealing with physical pain compared to those without pain were significantly more likely to report having a death wish $(\mathrm{p}=0.0005)$, current or lifetime suicidal ideation (both $\mathrm{p}<0.00001$ ), having made plans for suicide (current $\mathrm{p}=0.0008$, lifetime $\mathrm{p}<0.00001$ ), attempted suicide (current $\mathrm{p}<0.0001$, lifetime $\mathrm{p}<0.00001)$, and completed suicide $(\mathrm{p}=0.02)$ [23]. A retrospective study from the National Comorbidity Survey Replication $(n=5,692)$ retrieved data on painful conditions, non-painful conditions, and suicidal history [24]. In unadjusted logistic regression analyses, the presence of any pain condition was associated with both 12-month and lifetime suicidal ideation, suicide planning, and attempted suicide. Even when controlling for demographic, medical, and mental health covariates, the presence of a painful condition was significantly associated with lifetime suicidal ideation (odds ratio 1.4, 95\% CI, 1.1 to 1.8) [24]. Although not well studied, it may be that the duration of pain increases the risk of suicide [25]. Specific painful conditions may confer a greater or lesser risk of suicidality than others [14,15,20,26,27].

An emerging risk factor for suicide in chronic pain patients is sleeponset insomnia with daytime dysfunction combined with high pain intensity [20]. Since sleep may be a respite or "escape" for chronic pain patients, insomnia in this population may be perceived as particularly distressing.

It has been suggested that chronic pain as a persistent condition may reduce the patient's fear of death [29]. Thus, chronic pain is a source of distress, may reduce quality of life, can be comorbid with challenging mental health conditions, and, at the same time, serve to reduce the patient's natural fearfulness about death and dying.

\section{Dual diagnosis: Complicating the picture of suicidality among chronic pain patients}

Chronic pain is associated with comorbid conditions, such as depression, which may confer their own elevated risk of suicidality [30,31]. Among the general population, it has been estimated that about $90 \%$ of individuals who commit suicide have at least one psychiatric disorder at the time of death [32]. The overlap between mental health disorders and chronic pain is so prevalent that patients with both chronic pain and comorbid mental health disorders have a "dual diagnosis." In a study of two geographic regions using data from the Veterans Health Administration (VHA), 432 suicides over a seven-year period were evaluated, of which 381 had detailed chart information available [33]. In the latter group, $68.5 \%$ had documented mental health conditions compared to $31.5 \%$ who did not. Those with documented psychiatric conditions were also more likely to have reported pain, sleep problems, and suicidal ideation [33].

Chronic pain has been associated with major depressive disorder (MDD), although its association with certain other mental health conditions remains less clear $[34,35]$. Depressed patients have more complaints about pain and great impairment from pain than nondepressed patients [35]. Conversely, patients with more severe pain are more likely to have depressive symptoms [36]. When chronic pain is moderate to severe in intensity or when it reduces the patient's function or remains refractory to treatment, the patient generally exhibits more severe depressive symptoms and worse outcomes [35]. Even when the depression can be effectively treated, those patients in pain are more likely to relapse than those not dealing with pain [37]. Patients with even residual depressive symptoms are more likely to attempt suicide than those without depression [38]. From epidemiological evaluations of chronic pain patients treated in pain clinics, the prevalence of comorbid depression was $52 \%$ and the mean prevalence of pain in depressed patients was 65\% [35]. A primary care study reported that $69 \%$ of patients with MDD had at least moderate levels of pain, compared to about $39 \%$ who had moderate levels of pain but no MDD [35].

\section{This is your brain in pain and depression}

Many of the key areas of the brain affected by MDD and other mental health conditions have also been implicated in pain. For a person in pain, pain relief is perceived as both rewarding and pleasurable and is so encoded in the brain's reward circuits [40]. Structural and functional brain remodelling has been observed in some chronic pain patients. Chronic pain patients may also experience a dysregulation of the brain's 
Table 2. Risk factors for suicidality, including suicidal ideation, in chronic pain patients

\begin{tabular}{|c|c|c|}
\hline Domain & Risk Factors & Comments \\
\hline \multirow{3}{*}{ Pain } & Type of pain & $\begin{array}{l}\text { Migraine, back pain, and generalized pain may confer greater risk than other painful conditions, such as } \\
\text { neuropathy }\end{array}$ \\
\hline & Intensity of pain & Unclear how this affects suicidality, but in general severe pain is a greater risk than mild pain \\
\hline & Duration of pain & Prolonged pain may increase suicidality \\
\hline Sleep & Sleep-onset insomnia & $\begin{array}{l}\text { Since chronic pain patients may only find real relief during sleep, insomnia can be upsetting and exacerbate a } \\
\text { sense of hopelessness }\end{array}$ \\
\hline \multirow{7}{*}{ Psychological } & Helplessness & $\begin{array}{l}\text { The deeply held belief of a chronic pain patient that nothing can be done to control his or her pain and nothing } \\
\text { can change his or her current situation }\end{array}$ \\
\hline & Hopelessness & $\begin{array}{l}\text { The deeply held belief of a chronic pain patient that a positive or desirable result is impossible and will never be } \\
\text { achieved }\end{array}$ \\
\hline & Learned helplessness & $\begin{array}{l}\text { A psychological condition in which the chronic pain patients comes to believe that his or her pain is so far beyond } \\
\text { control that no attempts are made to change that condition }\end{array}$ \\
\hline & Desire to escape pain & A natural inclination to not suffer pain or do things that mitigate the pain \\
\hline & Catastrophizing & $\begin{array}{l}\text { An extreme belief that the pain or other related conditions will lead ultimately to an unavoidable disaster of } \\
\text { enormous proportions }\end{array}$ \\
\hline & Escape and avoidance & $\begin{array}{l}\text { A commonly reported motivation for suicidal behaviors is the urgent desire to escape an unbearable situation. }{ }^{28} \\
\text { Chronic pain patients "trapped" by their pain may experience an urgent desire to escape, but since escape is } \\
\text { impossible, the burden of chronic pain may seem unbearable }\end{array}$ \\
\hline & Poor problem-solving skills & $\begin{array}{l}\text { Chronic pain patients face numerous, dynamic, and sometimes formidable problems and the inability to solve } \\
\text { them or even address them effectively may contribute to both frustration and a sense of helplessness }\end{array}$ \\
\hline Mental health & Mental health conditions & $\begin{array}{l}\text { Numerous mental health conditions, such as major depressive disorder, are prevalent among chronic pain patients } \\
\text { and some may confer a risk of suicidality }\end{array}$ \\
\hline Pharmacology & $\begin{array}{l}\text { Certain drugs may exacerbate suicidality } \\
\text { and/or cause depressive symptoms }\end{array}$ & $\begin{array}{l}\text { Some drugs are associated with suicidal thoughts and actions } \\
\text { Long-term opioid therapy may be associated with hypogonadism, depressed libido, and sexual dysfunction which } \\
\text { may lead to depressive symptoms }\end{array}$ \\
\hline
\end{tabular}

reward circuits, which has been theorized as a reason for their reduced pain threshold over time [40]. Thus, it may be important to understand the commonalities in brain functions associated with both pain and MDD.

Nociception-afferent neural activation that transmits sensory information about noxious stimuli-differs from pain, which is the conscious experience [41,42]. Pain has an emotional and even intellectual context which is influenced by the patient's mindset, attitudes, mental health, cultural background, religious beliefs, and other factors. Advanced neuroimaging technology has provided vast insights into the brain and illuminated the cortical basis of pain perception. Indeed, in 1989, the presence of a pain-specific cortical matrix, originally named the "neuromatrix" was hypothesized [43]. Over time, the neuromatrix concept was refined into the "pain matrix," which defines a dedicated and specific pain-processing network within the brain [44-47]. It has been suggested that pain is experienced by the flow of information along the entire pain matrix rather than the specific isolated activation of a particular brain region [48].

The brain network associated with perception of acute pain in healthy subjects is distinct (at least partially) from the brain networks involved with chronic pain [49]. The neural network associated with chronic painful conditions engages some areas of the brain that are also associated with cognitive processes and emotional responses, which provides a physiological basis for the clinical observation that chronic pain often appears to have an emotional and contextual component absent in acute pain [49]. This shared neurobiology may explain why cognitive behavioural interventions can be effective in chronic pain patients (Figure 1).

\section{Amygdala}

This small area in the interior of the brain processes emotional responses and olfactory perceptions. It has been theorized that the amygdala attaches an emotional context to a pain experience [50]. Scanning studies suggest that MDD patients experience increased blood flow to the amygdala or changes in amygdala morphology [51-
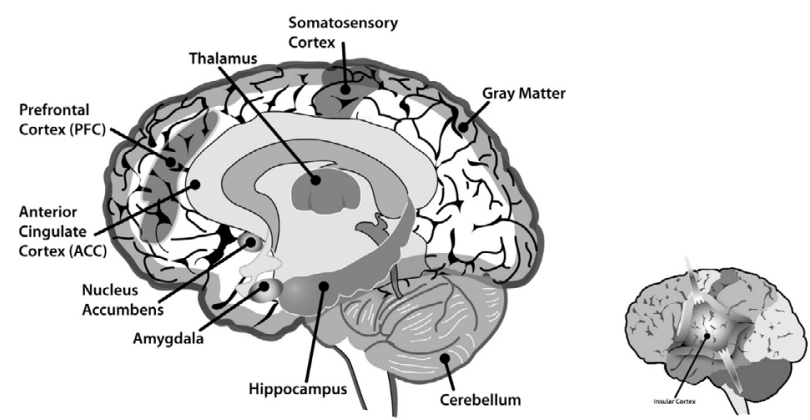

Figure 1. Key landmarks in the brain related to the pain pathways and mental health. The inset shows the insular cortex within the brain

54]. Suicidal MDD patients are more likely to have a larger amygdala volume than non-suicidal MDD patients [55]. Amygdala activity increases during stress, which might be precipitated during chronic pain [56]. The amygdala has been described as the crucial link between chronic pain and depression [57].

\section{Anterior cingulate cortex (ACC)}

This region supports cognitive decision-making, anticipation of rewards, empathy, and emotional response [58]. The ACC also helps process pain signals and may influence the patient's motor response to pain. Endogenous opioid activity in the ACC can relieve pain [59].

\section{Cerebellum}

Depressed patients typically exhibit a hypoactive cerebellum with reduced vermal volume $[58,60,61]$. The cerebellum may be activated when a patient experiences pain, a noxious stimulus, or in situations where there is empathy for another's pain [62].

\section{Gray matter}

The majority of neuronal cell bodies of the brain are found in the gray matter. Patients with chronic pain and MDD have reduced gray 
matter density, although the patterns of this loss and their potential commonalities have not yet been elucidated $[63,64]$.

\section{Hippocampus}

The hippocampus helps to form and store episodic memories [58]. Its volume is reduced in depressed patients. ${ }^{54,65,66}$ During painful experiences, the hippocampus may become activated [67]. Hippocampal dysfunction may result in an inappropriate response to pain [68].

\section{Insular cortex}

The insular cortex aids in the complex processing of multiple streams of information, such that an emotionally relevant context can be derived for a particular sensory experience [58]. The insular cortex may be activated when the patient perceives pain, and it may help the patient contextualize the pain [62].

\section{Nucleus accumbens}

Pain specialists are familiar with the role of the nucleus accumbens in addiction; it is part of the brain's reward and pleasure pathway and may also help to regulate emotional responses. ${ }^{58}$ The nucleus accumbens may increase negative responses, including the fear of pain [69].

\section{Prefrontal cortex (PFC)}

The prefrontal cortex regulates executive function, which includes the ability to plan, working memory, decision-making abilities, and deferred gratifications [58]. When a patient experiences pain, it activates the PFC which helps to process the affective perception of pain [62].

\section{Somatosensory cortex}

The somatosensory cortex is active in tactile sensory memories, and it is one of the main areas of the brain to help identify noxious stimuli, process the sensory perception of pain and pain intensity, and describe and differentiate pain $[62,70]$.

\section{Thalamus}

The role of the thalamus-the volume of which is reduced in depressed patients-is to relay sensory information from the body to the cerebral cortex [58]. The thalamus may play a role in both affective and sensory processing of pain signals [62].

\section{Sensory and affective aspects of pain and mental health disorders}

In the clinical setting, pain is almost exclusively measured in terms of its intensity; yet the sensory aspects of pain (its location, characteristics, waxing and waning, relieving or exacerbating mechanisms, and so on) often emerge as the more important symptoms in the treatment of chronic pain patients. In an observational clinical trial in Italy of 627 consecutive chronic pain patients admitted to psychosomatic medical counselling, patients were evaluated using the Italian version of the McGill Pain Questionnaire and subjected to the cold pressor test to evaluate their pain threshold; pain tolerance was defined as the time elapsed between immersion of a limb into cold water and the moment the limb was withdrawn [71]. Of the patient population, 381/627 (61\%) were diagnosed with some form of mood spectrum disorder based on the Mini-International Neuropsychiatric Interview (MINI) and the Hospital Anxiety Depression Scale (HADS) [72-73]. Patients with mood spectrum disorder demonstrated lower pain thresholds to the cold pressor test and increases in all dimensions of clinical pain versus control patients (those without mood spectrum disorders) although the difference between groups was not significant. Demographic data from the patient population indicate that the mood-spectrum disorder patients had a higher prevalence of current suicidal thoughts, whereas just under $2 \%$ of the control patients reported suicidal ideation [71].

While pain intensity is typically measured in clinical situations, pain also carries with it affective aspects, such as the way the patient thinks and feels about the pain. Affective response to pain actually relies on a different pathway in the central nervous system (CNS) than sensory perception, sharing the same neural pathway as depression [74]. Thus, negative affective response may help link pain to depression.

\section{Catastrophizing}

Catastrophizing among chronic pain patients may be defined as the belief that the pain and related dysfunction will unavoidably lead to enormous disaster. In some chronic pain patients, this can trigger a downward spiral that begins with catastrophizing, progresses to negative emotions, and culminates in suicidal ideation [6]. For example, a catastrophizing chronic pain patient might be a relatively functional individual with chronic pain who entertains thoughts of losing his job, then losing his house, and finally becoming completely dependent on hostile family members who do not wish to care for him. Catastrophizing may be associated with neuroses and a heightened negative affect [75,76]. Catastrophizing has been associated with increased pain severity, exacerbated muscle or joint tenderness, and pain-related disability. Catastrophizing may amplify pain signals processed by the central nervous system [77-85].

Catastrophizing has been associated with increased consumption of analgesics and intensified negative emotions [84]. Furthermore, the tendency to catastrophize has been associated with insomnia, another risk factor for suicidal ideation [86]. In a study of 360 rheumatology patients in South Korea, pain catastrophizing had a significant association with increased suicide risk [87]. In this study, suicidal risk was particularly heightened in patients who perceived that they would become burdens to their families. Similarly, a US study of 303 chronic pain patients found that both perceiving oneself to be a burden and distressed personal relationships were both significant predictors of suicidal ideation [88].

\section{Problem-solving deficits}

In very simplistic terms, suicide can sometimes be related to poor problem-solving skills [89]. Since the problems of chronic pain patients can be numerous, formidable, and dynamic, it seems reasonable to suggest that problem-solving deficits in chronic pain patients would contribute to their frustration and a sense of helplessness [90]. Likewise, depressed patients may exhibit impaired problem-solving abilities; poor problem-solving skills in depressed individuals may contribute to poor health, in that they may not always exercise good judgment about their lifestyle choices or medications [91].

\section{The role of insomnia in suicide among chronic pain patients}

A commonly reported motivation for suicidal behaviours is the urgent desire to escape an unbearable situation [28]. For some chronic pain patients, their only relief from their persistent torment is sleep, which may explain why insomnia has emerged as a potent risk factor for suicide in chronic pain patients [6]. Frequent sleep-onset insomnia (but not occasional insomnia or middle-of-the-night insomnia) has been linked to a five-fold increased risk of suicide in both the general and chronic pain populations [92]. In studies of depressed patients, poor-quality sleep, insomnia in general, and hypersomnia have been 
associated with an elevated risk for suicidality [93-95]. In the general population, even insufficient amounts of sleep may be linked to suicide; individuals who slept $<4$ hours per night had a three-fold increased risk of suicide compared to those who slept 6-8 hours per night, but even the 6-8-hour subjects were still 1.5 -times as likely to commit suicide compared to those who slept more than 8 hours per night [96]. A 19year study of 16,989 healthy subjects in France found that men with $\geq 3$ problems sleeping (the need for sleeping pills, not being able to fall asleep, taking too long to fall asleep, sleeping poorly, or waking too early) had a nearly five-fold increased risk of suicide [97]. (This study included both men and women but analysed data for men only since they comprised $74 \%$ of the study population.)

Sleep disorders are closely associated with depression, anxiety, and other mental health conditions, and it has been estimated that up to $60 \%$ to $80 \%$ of depressed patients experience insomnia $[98,99]$. Chronic pain patients likewise have very high rates of insomnia, ranging from $50 \%$ to $96 \%$ [100-103]. Insomnia has been recognized as a risk factor for suicide, specifically in chronic pain patients, indeed, sleep-onset insomnia may actually be a more robust predictor of suicidal ideation than depression among chronic pain patients $[6,20]$.

In a study of 88 chronic pain patients (66\% female), those reporting suicidal ideation were compared to those who did not report such thoughts [104]. Patients were assessed in five domains: sociodemographic status, physical health, psychological well-being (including whether they suffered depression), cognitive abilities (including catastrophizing), and the use of psychotropic and/or illicit drugs. Controlling for all physical health measures (pain intensity, pain duration, disability), the only significant predictor of suicidal ideation was poor sleep quality (odds ratio $1.29,95 \%$ confidence interval [CI], range 1.09 to 1.53 ) [104].

\section{Suicidality and pharmacological therapy}

Chronic pain patients frequently require polypharmacy, not only to control pain, but sometimes also to address comorbid conditions. Among the most frequently prescribed drugs in the chronic pain population are antidepressants (which have an analgesic effect distinct from their anti-depressive actions), anticonvulsants (for neuropathic pain), and opioid pain relievers.

\section{Antidepressants}

In a retrospective database study from the Department of Veterans Affairs database, 502,179 patients were identified who had diagnosed depression and a prescription for antidepressants in the time period from 1999 to 2004 [105]. Of this patient population, $47 \%$ had at least one outpatient mental health visit in the prior year, $13 \%$ had diagnosed posttraumatic stress syndrome, and $12 \%$ had diagnosed alcohol use disorder. Crude suicide rates varied by drug, ranging from 88 per 100000 patient-years to 247 per 100,000 person-years. The highest rates occurred with patients who just started mirtazapine, followed by venlafaxine, paroxetine, citalopram, sertraline, fluoxetine, and bupropion [105].

\section{Antiepileptic drugs}

Although the FDA issued an alert in January 2008 warning about the risk of suicide for many antiepileptic drugs, subsequent retrospective database analyses and reports have produced mixed evidence [106-110]. A case-control study from France matched patients with incident suicide attempts to demographically similar controls (506 patients who attempted suicide versus 2,829 controls) but found no statistically significant association between an attempted suicide and the use of antiepileptic medications (odds ration [OR] 1.5, 95\% CI, range 0.9-2.4) [111]. However, not all of these patients suffered from chronic pain, although some did. A meta-analysis (cohort of $5,130,795$ patients who received antiepileptic drugs for any reason) found no association between suicide and the use of these drugs [108]. A retrospective database study of 47,918 bipolar patients treated with antiepileptic medications found that these drugs did not increase suicidality compared to bipolar patients who did not take antiepileptic drugs and also compared to those who took lithium [112].

\section{Opioids}

Chronic pain patients who misuse or abuse opioids differ from those who take their medication only as prescribed in terms of their attentional and autonomic responses (reduced parasympathetic nervous activity) to opioid cues, that is, things like the sight of the pill, holding the prescription bottle, observing a doctor write a prescription, and so on [113-114]. It is not clear whether cue reactivity differs in chronic pain patients with and without suicidal ideation. However, the possible association among suicidality, opioid cravings, and cue reactivity may help better define the chronic pain patients at increased risk for suicide [115]. In a study of 115 chronic pain patients on longterm opioid therapy, those patients who sometimes tried to selfmedicate their suicidal feelings by abusing opioids were more likely to experience enhanced cravings and heightened opioid-associated cue reactivity [116]. Thus, exaggerated opioid cue-reactivity may suggest an attempt to self-medicate suicidal inclinations.

A retrospective data analysis of suicide mortality and opioid dose ( $n=123,946$ patients from a VHA database) found that higher doses of prescribed opioid analgesics could be correlated with increased risk of suicide, after controlling for demographic and clinical characteristics [117] (Table 3). Similar associations between analgesic dose and suicidality did not occur with acetaminophen, suggesting these findings are specific to opioid analgesics rather than other pain relievers. The reasons for this are unclear. It may be that higher doses of opioids suggest more intense pain and that severe pain intensity is the actual risk factor for suicide; in other words, higher opioid doses simply serve a marker for greater pain levels. Of course, high opioid doses do not necessarily mean that the patient had his pain fully controlled; because of pain severity, individual responses to opioids, opioidinduced hyperalgesia, and tolerance, patients on high-dose opioid therapy may still suffer uncontrolled pain. High-dose opioid therapy may be a marker for patients who lacked access to other pain-control options, such as cognitive or behavioural therapy, physical therapy, or multidisciplinary pain treatments. It has also been speculated that high doses of opioids decrease inhibitions in individuals who already harboured suicidal thoughts. Finally, giving patients in pain high doses of opioids provides them with ready access to a means to kill themselves by overdose, if they are so inclined [117]. Opioid analgesics are among the most frequently used substances to carry out suicide by overdose [118-119]. Thus, high-dose opioid therapy may be a risk factor for suicide in chronic pain patients.

Opioid use may be associated with distressing side effects that cause depressive symptoms. Sexual dysfunction and opioid-induced hormone

Table 3. In a retrospective VA study, higher doses of prescribed opioids could be correlated with increased suicide mortality [117]

\begin{tabular}{|c|c|c|c|}
\hline Opioid Dose & Hazard Ratio & Confidence Interval & Range \\
\hline 20 to $<50 \mathrm{mg} /$ day & 1.48 & $95 \%$ & $1.25-1.75$ \\
\hline 50 to $<100 \mathrm{mg}$ /day & 1.69 & $95 \%$ & $1.33-2.14$ \\
\hline$\geq 100 \mathrm{mg}$ /day & 2.15 & $95 \%$ & $1.64-2.81$ \\
\hline
\end{tabular}


deficiency are common in patients on long-term opioid therapy [120]. Opioids suppress the gonadotropin-releasing hormone, which causes the body to produce insufficient amounts of sex hormones, in some cases leading to depressed libido and/or opioid-associated hypogonadism [121]. The mechanism behind this action is the suppression of the hypothalamic-pituitary-gonadal and hypothalamic-pituitary-adrenal axes with resulting decreased levels of testosterone, follicle-stimulating hormone, luteinizing hormone, and dehydroepiandrosterone [122]. Testosterone therapy may be prescribed to address symptoms associated with quality of life, such as mood, sexual function, energy level, and libido, although the risks of this therapy may outweigh benefits [122]. Thus, depressive symptoms in opioid patients may in some cases trace back to organic factors, that is, mood disorders secondary to a medical condition.

In this connection, buprenorphine deserves to be specially noted. In a multisite, randomized, double-blind, placebo-controlled trial, suicidal patients without substance abuse were assigned randomly to receive either ultra-low-dose sublingual buprenorphine (initial dose was $0.1 \mathrm{mg}$ once or twice a day, mean final dosage was $0.44 \mathrm{mg} /$ day) or placebo in addition to other ongoing treatments. At two and four weeks, the low-dose buprenorphine patients scored significantly lower on the Beck Suicide Ideation Scale than placebo patients (mean difference $-4.3,95 \%$ confidence interval [CI], -8.5 to -0.2 at two weeks and $-7.1,95 \%$ CI, -12.0 to -2.3 at four weeks) [123]. The concomitant use of antidepressants did not affect this response to buprenorphine. These patients were not chronic pain patients, so it is unclear how lowdose sublingual buprenorphine would affect the chronic pain patient population with suicidal ideation.

Chronic pain patients may face unique challenges in terms of suicidal ideation as access to opioid pain medications becomes increasingly more difficult. In an online survey of fibromyalgia patients $(n=6,420), 27.2 \%(n=1,462)$ reported having thoughts of suicide since hydrocodone was rescheduled to a more restrictive (and less accessible) drug category [124]. Although data are incomplete for all chronic pain patients who rely on opioid analgesia, anecdotal reports suggest that many pain patients are deeply concerned that they might soon be denied adequate pain control.

\section{Suicide risk in specific chronic conditions}

In a retrospective review of 1,069 cases of suicide in which some decedents specified why they killed themselves, about $48 \%$ gave a nonmedical reason (financial distress, relationship problems, and so on), $33 \%$ stated a mental health reason, and $19 \%$ had a physical complaint [125]. The most commonly cited physical disorders leading to suicide were cancer (33\%), chronic pain (30\%), cardiovascular disorders $(28 \%)$, and metabolic disorders (25\%). Compared to those who committed suicide for mental health reasons, those who committed suicide on account of physical disorders tended to be older, male, and single or living alone [125]. While chronic pain was mentioned as a individual, specific cause for suicide, cancer, heart disease, and metabolic disorders may also be associated with pain. Of the decedents who gave mental health disorders as their reason for suicide, autopsies and evaluations of medical records revealed that many had concomitant physical problems, including chronic pain (19\%), cancer (8\%), heart disease (4\%), metabolic disorder (31\%) and other conditions, although these conditions were not mentioned as contributing factors to suicide. Individuals who had physical or mental health disorders the longest were most vulnerable: $61 \%$ and $71 \%$ of those with physical or mental health disorders, respectively, had their condition for at least two years before the suicide [125]. Certain painful conditions may have more direct associations with suicide than others. A brief summary appears below.

\section{Arthritis}

Arthritis is characterized by chronic musculoskeletal pain. The evidence for elevated suicide risk in arthritis patients is mixed. In a study of 21,744 individuals, those with arthritis were at greater risk for attempted suicide than those without arthritis (odds ratio 1.46) [126]. The prevalence for attempting suicide at least once in a lifetime was significantly higher in people with arthritis than those without arthritis, for both men $(3.9 \%$ vs. $2.0 \%$, respectively, $\mathrm{p}<0.001)$ and women $(5.3 \%$ vs. $3.2 \%, \mathrm{p}<0.001)$ [126]. Those arthritis patients who attempted suicide were more likely to be younger, poorer, less educated (high school dropout), be a substance abuser, have a history of anxiety and/ or depressive disorders, and report pain intensity levels of moderate to severe [126]. However, in a retrospective study based on the National Death Index and treatment records obtained from the Department of Veterans Affairs Healthcare System for 2005-2006 ( $n=4,863,086)$ arthritis was not associated with increased suicide risk, unlike certain other painful conditions [127].

\section{Back pain}

In the Veterans study $(n=4,863,086)$ described above, back pain in specific was significantly associated with an elevated risk of suicide (hazard ratio $1.33,99 \%$ CI, 1.22 to 1.45) [127]. Back pain may confer more of a risk on older than younger patients. In a study of 2,310 suicides committed in Finland from 1988 to 2007, investigators compared those individuals with diagnosed back pain $(n=133)$ and those with musculoskeletal pain other than back pain $(n=357)$ to those having no history of any back pain or musculoskeletal disorders $(n=1,820)$. In this study, individuals with back pain who committed suicide were 11 years older than reference patients [128].

\section{Cancer}

Overall, cancer patients have double the risk of committing suicide than healthy individuals [125]. Suicidal ideation among older adults has been associated with many types of cancer, specifically, cancers of the lung, gastrointestinal tract, breast, genitals, bladder, and lymph nodes [129]. Suicidality among cancer patients may be associated with pain but might also involve poor prognosis, dysfunction, depression, and a sense of hopelessness [129].

\section{Fibromyalgia}

A prospective Danish study of patients with confirmed or suspected fibromyalgia $(n=1,361)$ found no increased mortality in this population but did confirm an increased risk of suicide in female (but not male) patients [130]. The standardized mortality rate (SMR) in the overall study population was 1.3 (95\% CI, 0.9 to 1.8 ) but the SMR for suicide was 10.5 (95\% CI, 4.5 to 20.7$)$. In the subset of patients with a confirmed diagnosis of fibromyalgia $(\mathrm{n}=1,132)$ SMR was 6.5 (95\% CI, 1.8 to 6.7) but it was higher in those with suspected but unconfirmed fibromyalgia $(\mathrm{n}=106)$ at 19.6 (95\% CI, 2.2 to 70.8$)$ [130]. A possible explanation why the SMR is higher in those with unconfirmed fibromyalgia is that an undiagnosed chronic painful condition may be more frustrating and distressing than a definitive diagnosis, which would likely lead to specific treatment options or at least lend the symptoms credibility.

Similar findings occurred in a later study of 8,186 fibromyalgia patients, of whom $81 \%$ reported widespread pain at baseline [131] There was no difference in the SMR of this patient population compared to the general US population (stratified by age and sex), although 
fibromyalgia patients had both a higher rate of suicide (4.4\% compared to $1.4 \%$ of the general population, SMR 3.31 [ $95 \% \mathrm{CI}, 2.15$ to 5.11$]$ ) and a higher rate of accidental death $(7.1 \%$ versus $5.0 \%$ in the general population, SMR 1.45 [95\% CI, 1.02 to 2.06]) [131]. It is possible that some of the accidental deaths may have been unrecognized suicides.

\section{Headache and head pain}

In a study based on the National Comorbidity Survey-Replication, multivariate models were used to adjust for concurrent psychiatric disorders and chronic medical conditions. Over the 12-month study period, suicidal ideation was most associated with head pain (odds ratio $1.9,95 \% \mathrm{CI}$, range 1.2 to 3.0 ) as was attempted suicide (odds ratio $2.3,95 \% \mathrm{CI}$, range 1.2 to 4.4 ) [132]. In a study of 4,863,086 American veterans, migraine was associated with an elevated risk of suicide (hazard ratio $1.34,95 \%$ CI, 1.02 to 1.77) [127]. Lifetime headache frequency (all types of headache) was significantly greater in geriatric individuals ( $\geq 65$ years, excluding dementia patients) with a lifetime history of suicide attempts (odds ratio 1.92, range 1.17 to 3.15) [133].

\section{Inflammation}

Many psychiatric disorders have been associated with inflammatory processes and related aberrant cytokine levels. In a meta-analysis of 18 studies ( $n=845$ patients) levels of interleukin- $1 \beta(1 \mathrm{~L}-1 \beta)$ and interleukin-6 (IL-6) were found to be significantly higher in the serum and post-mortem brain samples of mental health patients with suicidality compared to mental health patients without suicidality $(\mathrm{p}<0.05)$ and compared to healthy control subjects $(\mathrm{p}<0.05)$ [134]. Cerebrospinal fluid levels of IL- 8 were significantly lower in suicidal patients versus healthy controls $(\mathrm{p}<0.05)$ [134]. Inflammation has also been associated with suicidality in MDD patients, specifically decreased IL-2 levels [135-136].

Vitamin D plays a role in immune support by helping to promote T-helper-2 (TH-2) phenotypes, may be inversely correlated with inflammation, and has been implicated in suicidality. In a study of 90 individuals who had either attempted suicide or were depressed but had not attempted suicide, versus healthy control patients, lower mean levels of vitamin D were associated with attempted suicide. In fact, 58\% of those who had attempted suicide were clinically deficient in vitamin D [137]. Note that this study included, but was not limited to, pain patients.

\section{Neuropathy}

Neuropathy can be extremely challenging to treat but in a Veterans', study described earlier, $(n=4,863,086)$ it was not associated with an increased risk of suicide [127].

\section{Obesity}

Obesity is a recognized risk factor for pain, including chronic pain, but it has not emerged as a clear risk factor for suicidality [138]. From a retrospective study of 4,005,640 patients in 2001-2002 obtained using the VHA database, body mass index (BMI) was inversely associated with increased risk of suicide. In this patient population, $1.3 \%$ were underweight, $24.3 \%$ were normal weight, $40.6 \%$ were overweight, and $33.8 \%$ were obese. Compared to normal-weight subjects, underweight individuals were at a higher risk of suicide (adjusted hazard ratio 1.17, 95\% CI, 1.01 to 1.36 ) but overweight and obese subjects had lower risks of suicide (adjusted hazard ratios 0.78 and 0.63 , respectively, $95 \% \mathrm{CI}$, ranges 0.74 to 0.82 and 0.60 to 0.66 , respectively) [139]. On the other hand, in a Canadian study (Canadian Community Health Survey Cycle 1.2 data, $n=36,984$ ), obesity was associated with both increased risk of lifetime psychiatric disorders as well as lifetime suicidal ideation and attempted suicide [140].

\section{Substance abuse}

A 2005-2006 VHA study $(\mathrm{n}=4,863,086)$ reported that men and women were both at increased risk for suicide if they were currently suffering from a substance abuse disorder involving alcohol, cocaine, cannabis, opioids, amphetamines, or sedatives [141]. Those who attempted suicide were more likely to abuse drugs and/or alcohol [142]. Prolonged substance abuse can trigger in the individual a cascade of serious financial, legal, domestic, and social problems which can act as powerful stressors [143]. Furthermore, many substances reduce inhibition and enhance impulsivity, and suicide may be viewed in some contexts as an impulsive act [143]. A study of 113 patients who attempted suicide found that the majority (70\%) made their most serious attempt at suicide during a period of heavy alcohol intake [144]. Factors that helped to identify these individuals who tried to commit suicide during a drinking binge were male gender, younger age, and greater degree of alcohol dependence [144].

In alcohol-dependent patients ( $\mathrm{n}=366,74 \%$ men) who had exhibited at least one suicidal behavior, physical pain could be associated with a lifetime history of suicidality [145]. In a case-comparison study from Sweden of people $\geq 70$ years treated in a hospital for attempted suicide $(n=103)$ compared to randomly selected subjects of similar age, alcohol use disorder was observed in significantly more patients who attempted suicide ( $26 \%$ vs. $4 \%$, odds ratio $10.5,95 \%$ CI, 4.9 to 22.5 ) [146].

\section{Discussion}

Suicidality is a complex phenomenon and can be associated with both chronic pain and mental health disorders. The association between suicide and chronic pain may not be as simple as a patient who simply has too much pain to bear, but rather may involve the multidimensional aspects of the pain experience, neural networks, and the interplay of other conditions such as substance abuse, inflammation, depression, disease processes, age, pharmacological therapy, and so on.

Since chronic pain patients are often treated with opioid analgesics, the recent public health discussions about limiting opioid access may be viewed by this population as particular stressors. In a survey of 6,420 fibromyalgia patients taken in the first 100 days following the rescheduling of hydrocodone from Schedule III to the more restrictive Schedule II by the Drug Enforcement Administration, 27.2\% of fibromyalgia patients reported having suicidal thoughts (compared to $4.4 \%$ of fibromyalgia patients in general) [124]. Tighter restrictions on pain relievers, particularly with the upshot that patients may no longer have access to effective pain control, may exacerbate frustration, despair, and even suicidality in this vulnerable population.

Some of the findings in this narrative review may be surprising. While headache is generally not considered a life-threatening or even serious medical problem, migraines are more associated with suicidality than many other chronic pain conditions. This supports the notion that migraine patients must be more effectively treated. On the other hand, neuropathic pain, which can be severe and is particularly challenging to treat, does not appear to elevate the patient's risk for suicide. Back pain is associated with an increased risk for suicide, but evidence is mixed for other types of musculoskeletal pain syndromes. Mental health disorders and chronic pain may involve some of the brain's same neural networks, which supports the notion that these conditions have far more overlap than currently recognized. 
It may behove clinicians to consider suicidality when dealing with chronic pain patients, particularly those patients with mental health comorbidities. Chronic pain patients may be extremely vulnerable to stressors, such as family stress, financial burdens, or fears for their future. Even chronic pain patients who are functional and effectively managed with analgesics may be vulnerable to stress about the possible loss of access to pain medicine. Furthermore, patients suffering from chronic pain may experience stress and frustration when their complaints are not believed by clinicians, employers, or family members. In a series of interviews with eight chronic pain patients, six reported having the experience of not being believed or dismissed by clinical staff [147]. Interestingly, the two patients in this study whom clinicians found credible had physical disabilities which made their painful symptoms more obvious. In some cases, pain medications were withheld. Patients in this situation can feel hurt, estranged, angry, and unfairly judged, all of which are powerful stressors in a vulnerable population with elevated risk of suicidality. One of these patients said that she was contemplating suicide-not specifically because of her pain but because no one took her seriously [147]. Of course, clinicians must exercise clinical discernment, in that drug seekers and malingerers are also encountered in practice.

Finally, there are limitations inherent to this sort of paper. This is a narrative review intended to address the broad issues of the topic rather than provide the depth of a systematic review or meta-analysis. Suicide overall is likely under-reported in that some overdose or traumatic deaths ruled accidental may have been suicide. Certainly, suicidal ideation and attempted suicide are under-reported because it is likely many people would not admit these things. It may also be that even when a person commits suicide and leaves a note stating reasons that these reasons may be poorly articulated, incomplete, or somewhat inaccurate. The risk of suicide in the chronic pain population is real and important, and there remains much more to learn about this subject.

\section{Conclusion}

Chronic pain patients have at least twice the risk of suicide than non-chronic pain patients, but these risks may be far more complex and multifaceted than simply unendurable pain. Dual diagnosis or the concomitant presence of mental health disorders and chronic pain likely exacerbates the risk of suicide. Evidence suggests depression and chronic (but not acute) pain may share some of the same neural networks. Certain conditions (such as migraine) may put a chronic pain patient at heightened risk for suicide although migraine is not itself a fatal condition. While severe pain increases the risk of suicide more than mild pain, there is no clear dose-dependent relationship between incremental steps in pain intensity and suicidality. Chronic pain patients are a vulnerable population, and it may be clinically important to consider their risks of suicidality during treatment.

\section{References}

1. WHO (2016) Suicide data. Mental health.

2. Centers for Disease Control and Prevention (2016) Suicide and self-inflicted injury. National Center for Health Statistics.

3. Curtin S, Warner, M (2016) Suicide rates for females and males by race and ethnicity: United States, 1999 and 2014.

4. National Institute of Mental Health (2017) Suicidal thoughts and behaviors among U.S. adults.

5. Bryan CJ, Rudd MD, Wertenberger E (2013) Reasons for suicide attempts in a clinical sample of active duty soldiers. J Affect Disord 144: 148-152. [Crossref]

6. Tang NK, Crane C (2006) Suicidality in chronic pain: a review of the prevalence, risk factors and psychological links. Psychol Med 36: 575-586. [Crossref]
7. Edwards RR, Smith MT, Kudel I, Haythornthwaite J (2006) Pain-related catastrophizing as a risk factor for suicidal ideation in chronic pain. Pain 126: 272-279. [Crossref]

8. Sher L (2004) Preventing suicide. QJM 97: 677-680. [Crossref]

9. Coryell W, Young EA (2005) Clinical predictors of suicide in primary major depressive disorder. J Clin Psychiatry 66: 412-417. [Crossref]

10. Hayes LM (2005) Juvenile suicide in confinement in the United States results from a national survey. Crisis 26: 146-148. [Crossref]

11. Nordstrom P, Asberg M, Aberg-Wistedt A, Nordin C (1995) Attempted suicide predicts suicide risk in mood disorders. Acta psychiatrica Scandinavica 92: 345-350.

12. Oquendo MA, Galfalvy H, Russo S, Ellis SP, Grunebaum MF, et al. (2004) Prospective study of clinical predictors of suicidal acts after a major depressive episode in patients with major depressive disorder or bipolar disorder. Am J of Psych 161: 1433-1441. [Crossref]

13. Bryan C, Rudd M (2016) The importance of temporal dynamics in the transition from suicidal thought to behavior. Clin Psychol Sci Pract 23: 21-25.

14. Breslau N (1992) Migraine, suicidal ideation, and suicide attempts. Neurology 42: 392395. [Crossref]

15. Magni G, Rigatti-Luchini S, Fracca F, Merskey H (1998) Suicidality in chronic abdominal pain: an analysis of the Hispanic Health and Nutrition Examination Survey (HHANES). Pain 76: 137-144. [Crossref]

16. Brunner J, Bronisch T (1999) [Neurobiological correlates of suicidal behavior. Fortschr Neurol Psychiatr 67: 391-412. [Crossref]

17. Blumenthal SJ, Kupfer DJ (1988) Overview of early detection and treatment strategies for suicidal behavior in young people. J Youth Adolesc 17: 1-23. [Crossref]

18. Blumenthal SJ, Kupfer DJ (1986) Generalizable treatment strategies for suicidal behavior. Ann N Y Acad Sci 487: 327-340. [Crossref]

19. Snowdon J, Baume P (2002) A study of suicides of older people in Sydney. Int J Geriatr Psychiatry 17: 261-269. [Crossref]

20. Smith M, Perlis M, Haythornthwaite J (2004) Suicidal ideation in outpatients with chronic musculoskeletal pain: an exploratory study of the role of sleep onset insomnia and pain intensity. Clin J of Pain 20: 111-118. [Crossref]

21. Smith MT, Edwards RR, Robinson RC, Dworkin RH (2004) Suicidal ideation, plans, and attempts in chronic pain patients: factors associated with increased risk. Pain 111: 201-208. [Crossref]

22. Ilgen MA, Zivin K, Austin KL, Bohnert AS, Czyz EK, et al. (2010) Severe pain predicts greater likelihood of subsequent suicide. Suicide Life Threat Behav 40: 597608. [Crossref]

23. Calati R, Laglaoui Bakhiyi C, Artero S, Ilgen M, Courtet P (2015) The impact of physical pain on suicidal thoughts and behaviors: Meta-analyses. J Psychiatr Res 71: 16-32. [Crossref]

24. Braden JB, Sullivan MD (2008) Suicidal thoughts and behavior among adults with self-reported pain conditions in the national comorbidity survey replication. Pain 9: 1106-1115. [Crossref]

25. Treharne G, Lyons A, Kitas G (2000) Suicidal ideation in patients with rheumatoid arthritis. Research may help identify patients at high risk. Br Med J 321: 18. [Crossref]

26. Penttinen J (1995) Back pain and risk of suicide among Finnish farmers. Am J Public Health 85: 1452-1453. [Crossref]

27. Macfarlane G, McBeth J, Silman A (2001) Widespread body pain and mortality: prospective population-based study. $\mathrm{Br}$ Med J 323: 1-5.

28. Hjelmeland H, Hawton K, Nordvik H, Bille-Brahe U, De Leo D, et al. (2002) Why people engage in parasuicide: a cross-cultural study of intentions. Suicide Life Threat Behav 32: 380-393. [Crossref]

29. Hooley JM, Franklin JC, Nock MK (2014) Chronic pain and suicide: understanding the association. Curr Pain Headache Rep 18: 435. [Crossref]

30. Tang NK, Crane C (2006) Suicidality in chronic pain: a review of the prevalence, risk factors and psychological links. Psychol Med 36: 575-586. [Crossref]

31. Hassett AL, Aquino JK, Ilgen MA (2014) The risk of suicide mortality in chronic pain patients. Curr Pain Headache Rep 18: 436. [Crossref]

32. Barraclough B, Bunch J, Nelson B, Sainsbury P (1974) A hundred cases of suicide clinical aspects. Br J Psychiatry 125: 355-373. [Crossref] 
33. Britton PC, Ilgen MA, Valenstein M, Knox K, Claassen CA, et al. (2012) Differences between veteran suicides with and without psychiatric symptoms. Am Jn Pub Health S1: 125-130. [Crossref]

34. Arnow BA, Hunkeler EM, Blasey CM, Lee J, Constantino MJ, et al. (2006) Comorbid depression, chronic pain, and disability in primary care. Psychosom Med 68: 262-268. [Crossref]

35. Bair MJ, Robinson RL, Katon W, Kroenke K (2003) Depression and pain comorbidity: a literature review. Arch Intern Med 163: 2433-2445. [Crossref]

36. Gambassi G (2009) Pain and depression: the egg and the chicken story revisited. Arch Gerontol Geriatr S1: 103-112. [Crossref]

37. Geerlings SW, Twisk JW, Beekman AT, Deeg DJ, van Tilburg W (2002) Longitudinal relationship between pain and depression in older adults: sex, age and physical disability. Soc Psychiatry Psychiatr Epidemiol 37: 23-30. [Crossref]

38. Kennedy N, Foy K (2005) The impact of residual symptoms on outcome of major depression. Current Psychiatry Reports 7: 441-446.

39. Gameroff MJ, Olfson M (2006) Major depressive disorder, somatic pain, and health care costs in an urban primary care practice. J Clin Psychiatry 67: 1232-1239. [Crossref]

40. Navratilova E, Atcherley CW, Porreca F (2015) Brain Circuits Encoding Reward from Pain Relief. Trends Neurosci 38: 741-750. [Crossref]

41. Treede RD (2006) Chapter 1 Pain and hyperalgesia: definitions and theories. Handb Clin Neurol 81: 3-10. [Crossref]

42. Iannetti GD, Mouraux A (2010) From the neuromatrix to the pain matrix (and back). Exp Brain Res 205: 1-12. [Crossref]

43. Melzack R (1989) Phantom limbs, the self and the brain. Can Psychol 30: 1-16.

44. Talbot JD, Marrett S, Evans AC, Meyer E, Bushnell MC, et al. (1991) Multiple representations of pain in human cerebral cortex. Science 251: 1355-1358. [Crossref]

45. Whyte J (2008) Clinical implications of the integrity of the pain matrix. Lancet Neurol 7: 979-980. [Crossref]

46. Boly M, Faymonville ME, Schnakers C, Peigneux P, Lambermont B, et al. (2008) Perception of pain in the minimally conscious state with PET activation: an observational study. Lancet Neurol 7: 1013-1020. [Crossref]

47. Brooks J, Tracey I (2005) From nociception to pain perception: imaging the spinal and supraspinal pathways. J Anat 207: 19-33. [Crossref]

48. Tracey I (2005) Nociceptive processing in the human brain. Curr Opin Neurobiol 15: 478-487. [Crossref]

49. Apkarian AV (2010) Human brain imaging studies of chronic pain: Translational opportunities translational pain research: From mouse to man. Boca Raton, FL: Llc.

50. Moskvina V, Farmer A, Swainson V, O'Leary J, Gunasinghe C, et al. (2007) Interrelationship of childhood trauma, neuroticism, and depressive phenotype. Depression and Anxiety 24: 163-168. [Crossref]

51. Drevets W, Videen T, Price J, Preskorn SH, Carmichael T, et al. (1992) A functiona anatomical study of unipolar depression. J Neuroscience 12: 3628-3641. [Crossref]

52. Tang Y, Wang F, Xie G, Liu J, Li L, et al (2007) Reduced ventral anterior cingulate and amygdala volumes in medication-naive females with major depressive disorder. Psychiatry Research 156: 83-86. [Crossref]

53. Rosso I, Cintron C, Steingard R, Renshaw P, Young A, et al. (2005) Amygdala and hippocampus volumes in pediatric major depression. Biological Psychiatry 57: 21-26. [Crossref]

54. Lange C, Irle E (2004) Enlarged amygdala volume and reduced hippocampal volume in young women with major depression. Psychol Med 34: 1059-1064. [Crossref]

55. Monkul S, Hatch J, Nicoletti M, Spence S, Brambilla P, et al (2007) Fronto-limbic brain structures in suicidal and non-suicidal female patients with major depressive disorder. Mol Psychiatry 12: 360-366. [Crossref]

56. Diamond D, Campbell A, Park CW, Vouimba R (2004) Preclinical research on stress, memory, and the brain in the development of pharmacotherapy for depression. European Neuropsychopharmacol 14S: 491-495. [Crossref]

57. Neugebauer V, Li W, Bird GC, Han JS (2004) The amygdala and persistent pain. Neuroscientist 10: 221-234. [Crossref]

58. Nemeroff C. Part IV: Mood Disorders. In: Charney D, Nestler E, eds (2004) Neurobiology of Mental Illness. 2nd ed. New York: Oxford University Press.
59. Navratilova E, Xie JY, Meske D, Qu C, Morimura K, et al. (2015) Endogenous opioid activity in the anterior cingulate cortex is required for relief of pain. $J$ Neurosci 35 : 7264-7271. [Crossref]

60. Drevets W, Price J, Simpson J Jr, Todd RD, Reich T, et al. (1997) Sugenual prefrontal cortex abnormalities in mood disorders. Nature 386: 824-827. [Crossref]

61. Fitzgerald PB, Laird AR, Maller J, Daskalakis ZJ (2008) A meta-analytic study of changes in brain activation in depression. Hum Brain Mapp 29: 683-695. [Crossref]

62. Kenneth C, Tri T (2006) Cortical mechanisms mediating acute and chronic pain in humans. In: Cervero F, Jensen T, eds. Handbook of Clinical Neurology. Boston, Massachusetts: Elsevier.

63. Apkarian AV, Sosa Y, Sonty S, Levy RM, Harden RN, et al. (2004) Chronic back pain is associated with decreased prefrontal and thalamic gray matter density. J Neurosci 24: 10410-10415. [Crossref]

64. Grieve SM, Korgaonkar MS, Koslow SH, Gordon E, Williams LM (2013) Widespread reductions in gray matter volume in depression. Neuroimage Clin 3: 332-339. [Crossref]

65. Bremner D, Narayan M, Anderson E, Staib LH, Miller H, et al. (2000) Hippocampa volume reduction in major depression. American J Psychiatry 157:115-118. [Crossref]

66. Sheline YI, Gado MH, Kraemer HC (2003) Untreated depression and hippocampal volume loss. Am J Psychiatry 160: 1516-1518. [Crossref]

67. Bingel U, Quante M, Knab R, Bromm B, Weiller C, et al. (2002) Subcortical structures involved in pain processing: evidence from single-trial fMRI. Pain Management Nursing 99: 313-321.

68. Ploghaus A, Narain C, Beckmann CF, Clare S, Bantick S, et al. (2001) Exacerbation of pain by anxiety is associated with activity in a hippocampal network. $J$ Neurosci 21 : 9896-9903. [Crossref]

69. Scott D, Heitzeg MM, Koeppe RA, Stohler CS, Zubieta JK (2006) Variations in the human pain stress experience mediated by ventral and dorsal basal ganglia dopamine activity. J Neurosci 26: 10789-10795. [Crossref]

70. Kostopoulos P, Albanese M, Petrides M (2007) Ventrolateral prefrontal cortex and tactile memory disambiguation in the human brain. Proceedings of the National Academy of Sciences of the United States of America. 104: 10223-10228.

71. Ciaramella A (2017) Mood Spectrum Disorders and Perception of Pain. Psychiatr $Q$ 88: 687-700. [Crossref]

72. Sheehan D, Lecrubier Y, Sheehan K, Amorim P, Janavs J, et al. (1998) The miniinternational neuropsychiatric interview (M.I.N.I.): the development and validation of a structured diagnostic psychiatric interview for DSM-IV and ICD-10. J Clin Psychiatry 59: 22-33. [Crossref]

73. Zigmond AS, Snaith RP (1983) The hospital anxiety and depression scale. Acto Psychiatr Scand 67: 361-370. [Crossref]

74. Robinson MJ, Edwards SE, Iyengar S, Bymaster F, Clark M, et al. (2009) Depression and pain. Front Biosci (Landmark Ed) 14: 5031-5051. [Crossref]

75. Goubert L, Crombez G, Van Damme S (2004) The role of neuroticism, pain catastrophizing and pain-related fear in vigilance to pain: a structural equations approach. Pain 107: 234-241. [Crossref]

76. Esteve MR, Camacho L (2008) Anxiety sensitivity, body vigilance and fear of pain Behav Res Ther 46: 715-727. [Crossref]

77. Gracely RH, Geisser ME, Giesecke T, Grant MA, Petzke F, et al. (2004) Pain catastrophizing and neural responses to pain among persons with fibromyalgia. Brain 127: 835-843. [Crossref]

78. Schochat T, Raspe H (2003) Elements of fibromyalgia in an open population. Rheumatology (Oxford) 42: 829-835. [Crossref]

79. Gracely RH, Grant MA, Giesecke T (2003) Evoked pain measures in fibromyalgia. Best Pract Res Clin Rheumatol 17: 593-609. [Crossref]

80. Giesecke T, Williams DA, Harris RE, Cupps TR, Tian X, et al. (2003) Subgrouping of fibromyalgia patients on the basis of pressure-pain thresholds and psychological factors. Arthritis Rheum 48: 2916-2922. [Crossref]

81. Keefe FJ, Lefebvre JC, Egert JR, Affleck G, Sullivan MJ, et al. (2000) The relationship of gender to pain, pain behavior, and disability in osteoarthritis patients: the role of catastrophizing. Pain 87: 325-334. [Crossref]

82. Pavlin DJ, Sullivan MJ, Freund PR, Roesen K (2005) Catastrophizing: a risk factor for postsurgical pain. Clin J Pain 21: 83-90. [Crossref]

83. Edwards RR, Bingham CO 3rd, Bathon J, Haythornthwaite JA (2006) Catastrophizing and pain in arthritis, fibromyalgia, and other rheumatic diseases. Arthritis and Rheumatism 55: 325-332. [Crossref] 
84. Sullivan MJ, Thorn B, Haythornthwaite JA, Keefe F, Martin M, et al. (2001) Theoretical perspectives on the relation between catastrophizing and pain. Clin J Pain 17: 52-64. [Crossref]

85. Geisser ME, Casey KL, Brucksch CB, Ribbens CM, Appleton BB, et al. (2003) Perception of noxious and innocuous heat stimulation among healthy women and women with fibromyalgia: association with mood, somatic focus, and catastrophizing. Pain 102: 243-250. [Crossref]

86. MacDonald S, Linton SJ, Jansson-Frojmark M (2010) Cognitive vulnerability in the development of concomitant pain and sleep disturbances. Brit J Health Psych 15: 417 434. [Crossref]

87. Shim E, Song YW, Park SH, Lee KM, Go DJ, et al. (2017) Examining the Relationship Between Pain Catastrophizing and Suicide Risk in Patients with Rheumatic Disease: The Mediating Role of Depression, Perceived Social Support, and Perceived Burdensomeness. Internat J Behav Med 24: 501-512. [Crossref]

88. Wilson KG, Kowal J, Henderson PR, McWilliams LA, Peloquin K (2013) Chronic pain and the interpersonal theory of suicide. Rehabilitation Psychology 58: 111-115. [Crossref]

89. Pollock LR, Williams JM (1998) Problem solving and suicidal behavior. Suicide Life Threat Behav 28: 375-387. [Crossref]

90. Witty T, Heppner P, Bernard C, Thoreson R (2001) Problem-solving appraisal and psychological adjustment of persons with chronic low-back pain. J Clin Psychol Med Settings 8: 149-160.

91. Shin N, Hill-Briggs F, Langan S, Payne JL, Lyketsos C, et al. (2017) The association of minor and major depression with health problem-solving and diabetes self-care activities in a clinic-based population of adults with type 2 diabetes mellitus. J Diabetes Complications 31: 880-885. [Crossref]

92. Bjørngaard JH, Bjerkeset O, Romundstad P, Gunnell D (2011) Sleeping problems and suicide in 75,000 Norwegian adults: a 20 year follow-up of the HUNT I study. Sleep 34: 1155-1159. [Crossref]

93. AÄŸarg MY, Kara H, Solmaz M (1997) Sleep disturbances and suicidal behavior in patients with major depression. J Clin Psychiatry 58: 249-251. [Crossref]

94. Agargun MY, BeÅŸiroÄŸlu L (2005) Sleep and suicidality: do sleep disturbances predict suicide risk? Sleep 28: 1039-1040. [Crossref]

95. Chellappa SL, Araujo JF (2007). Sleep disorders and suicidal ideation in patients with depressive disorder. Psychiatry Research 153: 131-136.

96. Gunnell D, Chang SS, Tsai MK, Tsao CK, Wen CP (2013). Sleep and suicide: an analysis of a cohort of 394,000 Taiwanese adults. Soc Psychiatry Psychiatr Epidemiol 48: 1457-1465. [Crossref]

97. Rod NH, Vahtera J, Westerlund H, Kivimaki M, Zins M, et al. (2011) Sleep disturbances and cause-specific mortality: Results from the GAZEL cohort study. Am J Epidemiol 173: 300-309. [Crossref]

98. Benca RM, Peterson MJ (2008) Insomnia and depression. Sleep Med 9 Suppl 1: S3-9. [Crossref]

99. Luca A, Luca M, Calandra C (2013) Sleep disorders and depression: brief review of the literature, case report, and nonpharmacologic interventions for depression. Clin Interv Aging 8:1033-1039. [Crossref]

100. Breivik H, Collett B, Ventafridda V, Cohen R, Gallacher D (2006) Survey of chronic pain in Europe: prevalence, impact on daily life, and treatment. Eur J Pain 10: 287 333. [Crossref]

101. Bigatti SM, Hernandez AM, Cronan TA, Rand KL (2008) Sleep disturbances in fibromyalgia syndrome: relationship to pain and depression. Arthritis Rheum 59: 961-967. [Crossref]

102. Ohayon MM (2005) Relationship between chronic painful physical condition and insomnia. J Psychiatr Res 39: 151-159. [Crossref]

103. Tang NK, Wright KJ, Salkovskis PM (2007) Prevalence and correlates of clinical insomnia co-occurring with chronic back pain. J Sleep Res 16: 85-95. [Crossref]

104. Racine M, Choinière M, Nielson WR (2014) Predictors of suicidal ideation in chronic pain patients: an exploratory study. Clin J Pain 30: 371-378. [Crossref]

105. Valenstein M, Kim HM, Ganoczy D, Eisenberg D, Pfeiffer PN, et al. (2012) Antidepressant agents and suicide death among US Department of Veterans Affairs patients in depression treatment. J Clin Psychopharm 32: 346-353. [Crossref]

106. Hesdorffer DC, Kanner AM (2009) The FDA alert on suicidality and antiepileptic drugs: Fire or false alarm? Epilepsia 50: 978-986. [Crossref]
107. Patorno E, Bohn RL, Wahl PM, Avorn J, Patrick AR, et al. (2010) Anticonvulsant medications and the risk of suicide, attempted suicide, or violent death. JAMA 303 1401-1409. [Crossref]

108. Arana A, Wentworth CE, Ayuso-Mateos JL, Arellano FM (2010) Suicide-related events in patients treated with antiepileptic drugs. NE J Med 363: 542-551.

109. Andersohn F, Schade R, Willich SN, Garbe E (2010) Use of antiepileptic drugs in epilepsy and the risk of self-harm or suicidal behavior. Neurology 75: 335-340. [Crossref]

110. Bell GS, Mula M, Sander JW (2009) Suicidality in people taking antiepileptic drugs: What is the evidence? CNS Drugs 23: 281-292. [Crossref]

111. Grimaldi-Bensouda L, Nordon C, Rossignol M, Jardon V, Boss V, et al. (2017) Antiepileptic drugs and risk of suicide attempts: a case-control study exploring the impact of underlying medical conditions. Pharmacoepidemiol Drug Saf 26: 239-247. [Crossref]

112. Gibbons RD, Hur K, Brown CH, Mann JJ (2009) Relationship between antiepileptic drugs and suicide attempts in patients with bipolar disorder. Arch Gen Psychiatry 66: 1354-1360. [Crossref]

113. Garland EL, Froeliger BE, Passik SD, Howard MO (2013) Attentional bias for prescription opioid cues among opioid dependent chronic pain patients. J Behav Med 36: 611-620. [Crossref]

114. Garland EL, Brown SM, Howard MO (2015) Thought suppression as a mediator of the association between depressed mood and prescription opioid craving among chronic pain patients. J Behav Med 39: 128-38. [Crossref]

115. Ray WA, Chung CP, Murray KT, Hall K, Stein CM (2016) Prescription of longacting opioids and mortality in patients with chronic noncancer pain. JAMA 315 : 2415-2423. [Crossref]

116. Garland EL, Riquino MR, Priddy SE, Bryan CJ (2017) Suicidal ideation is associated with individual differences in prescription opioid craving and cue-reactivity among chronic pain patients. J Addict Dis 36: 23-29. [Crossref]

117. Ilgen MA, Bohnert AS, Ganoczy D, Bair MJ, McCarthy JF, et al. (2016) Opioid dose and risk of suicide. Pain 157: 1079-1084. [Crossref]

118. Sinyor M, Howlett A, Cheung AH, Schaffer A (2012) Substances used in completed suicide by overdose in Toronto: an observational study of coroner's data. Can J Psychiatry 57: 184-191. [Crossref]

119. Shields LB, Hunsaker DM, Hunsaker JC 3rd, Ward MK (2006) Toxicologic findings in suicide: a 10-year retrospective review of Kentucky medical examiner cases. Am J Forensic Med Pathol 27: 106-112. [Crossref]

120. Birthi P, Nagar VR, Nickerson R, Sloan PA (2015) Hypogonadism associated with long-term opioid therapy: A systematic review. J Opioid Manag 11: 255-278. [Crossref]

121. Ali K, Raphael J, Khan S, Labib M, Duarte R, et al. (2016) The effects of opioids on the endocrine system: an overview. Postgrad Med J 92: 677-681. [Crossref]

122. Murphy EN, Miranda R (2014) Doubts about treating hypogonadism due to longterm opioid use with testosterone therapy: a teachable moment. JAMA Intern Med 174: 1892-1893. [Crossref]

123. Yovell Y, Bar G, Mashiah M, Baruch Y, Briskman I et al. (2016) Ultra-Low-Dose Buprenorphine as a Time-Limited Treatment for Severe Suicidal Ideation: A Randomized Controlled Trial. Am J Psychiatry 173: 491-498. [Crossref]

124. Chambers J, Gleason RM, Kirsh KL, Twillman R, Webster L, et al. (2005) An Online Survey of Patients' Experiences Since the Rescheduling of Hydrocodone: The Firs 100 Days. Pain Med 17: 1686-1693. [Crossref]

125. Fegg M, Kraus S, Graw M, Bausewein C (2016) Physical compared to menta diseases as reasons for committing suicide: a retrospective study. BMC Palliat Care 15: 14. [Crossref]

126. Fuller-Thomson E, Ramzan N, Baird SL (2016) Arthritis and suicide attempts: findings from a large nationally representative Canadian survey. Rheum Intl 36: 12371248. [Crossref]

127. Ilgen MA, Kleinberg F, Ignacio RV, Bohnert AS, Valenstein M, et al. (2013) Noncancer pain conditions and risk of suicide. JAMA Psychiatry 70: 692-697. [Crossref]

128. Löfman S, Räsänen P, Hakko H, Mainio A (2011) Suicide among persons with back pain: a population-based study of 2310 suicide victims in Northern Finland. Spine (Phila Pa 1976) 36: 541-548. [Crossref] 
129. Fassberg MM, Cheung G, Canetto SS, Erlangsen A, Lapierre S, et al. (2016) A systematic review of physical illness, functional disability, and suicidal behaviour among older adults. Aging Ment Health 20: 166-194. [Crossref]

130. Dreyer L, Kendall S, Danneskiold-Samsoe B, Bartels EM, Bliddal H (2010) Mortality in a cohort of Danish patients with fibromyalgia: increased frequency of suicide. Arthritis Rheum 62: 3101-3108. [Crossref]

131. Wolfe F, Hassett AL, Walitt B, Michaud K (2011) Mortality in fibromyalgia: a study of 8,186 patients over thirty-five years. Arthritis Care Res (Hoboken) 63: 94-101. [Crossref]

132. Ilgen MA, Zivin K, McCammon RJ, Valenstein M (2008) Pain and suicidal thoughts, plans and attempts in the United States. Gen Hosp Psychiatry 30: 521527. [Crossref]

133. Calati R, Courtet P, Norton J, Ritchie K, Artero S (2017) Association between lifetime headache and history of suicide attempts in the elderly. Eur Psychiatry 41: 132-139. [Crossref]

134. Black C, Miller BJ (2015) Meta-Analysis of Cytokines and Chemokines in Suicidality: Distinguishing Suicidal Versus Nonsuicidal Patients. Biol Psychiatry 78 : 28-37. [Crossref]

135. O’Donovan A, Rush G, Hoatam G, Hughes BM, McCrohan A, et al. (2013) Suicidal ideation is associated with elevated inflammation in patients with major depressive disorder. Depress Anxiety 30: 307-314. [Crossref]

136. Kim YK, Lee SW, Kim SH, Shim SH, Han SW, et al. (2008) Differences in cytokines between non-suicidal patients and suicidal patients in major depression. Prog Neuropsychopharmacol Biol Psychiatry 32: 356-361. [Crossref]

137. Grudet C, Malm J, Westrin A, Brundin L (2014) Suicidal patients are deficient in vitamin $\mathrm{D}$, associated with a pro-inflammatory status in the blood. Psychoneuroendocrinology 50: 210-219. [Crossref]
138. Suri P, Boyko EJ, Smith NL, Jarvik JG, Williams FM, et al. (2017) Modifiable risk factors for chronic back pain: insights using the co-twin control design. Spine $J 17$ : 4-14. [Crossref]

139. McCarthy JF, Ilgen MA, Austin K, Blow FC, Katz IR (2014) Associations between body mass index and suicide in the veteran's affairs health system. Obesity (Silver Spring) 22: 269-276. [Crossref]

140. Mather AA, Cox BJ, Enns MW, Sareen J (2009) Associations of obesity with psychiatric disorders and suicidal behaviors in a nationally representative sample. $J$ Psychosom Res 66: 277-285. [Crossref]

141. Bohnert KM, Ilgen MA, Louzon S, McCarthy JF, Katz IR (2017) Substance use disorders and the risk of suicide mortality among men and women in the US Veterans Health Administration. Addiction 112: 1193-1201. [Crossref]

142. Cavanagh JT, Carson AJ, Sharpe M, Lawrie SM (2003) Psychological autopsy studies of suicide: a systematic review. Psychol Med 33: 395-405. [Crossref]

143. CDC (2011) Suicides due to alcohol and/or drug overdose; a data brief from the National Violent Death Reporting System. CDC Stacks, Public Health Publications.

144. Klimkiewicz A, Ilgen MA, Bohnert AS, Jakubczyk A, Wojnar M, et al. (2012) Suicide attempts during heavy drinking episodes among individuals entering alcohol treatment in Warsaw, Poland. Alcohol and Alcoholism 47: 571-576. [Crossref]

145. Jakubczyk A, Ashrafioun L, Ilgen M, Kopera M, Klimkiewicz A, et al. (2016) Physical Pain and History of Suicidal Behaviors in Alcohol-Dependent Patients Entering Treatment in Poland. Substance Use and Misuse 51: 1307-1317. [Crossref]

146. Morin J, Wiktorsson S, Marlow T, Olesen PJ, Skoog I, et al. (2013) Alcohol use disorder in elderly suicide attempters: a comparison study. Am J Geriatric Psychiatry 21: 196-203. [Crossref]

147. Clarke K, Iphofen R (2008) The effects of failing to believe patients' experience of chronic pain. Nursing Times 104: 30-31.

Copyright: (C) 2018 Pergolizzi JV. This is an open-access article distributed under the terms of the Creative Commons Attribution License, which permits unrestricted use, distribution, and reproduction in any medium, provided the original author and source are credited. 